\title{
Active Source Requirements for Assay of Sludge Drums on the BIR WIT System
}

\author{
G. P. Roberson \\ D. C. Camp
}

April 27, 1998

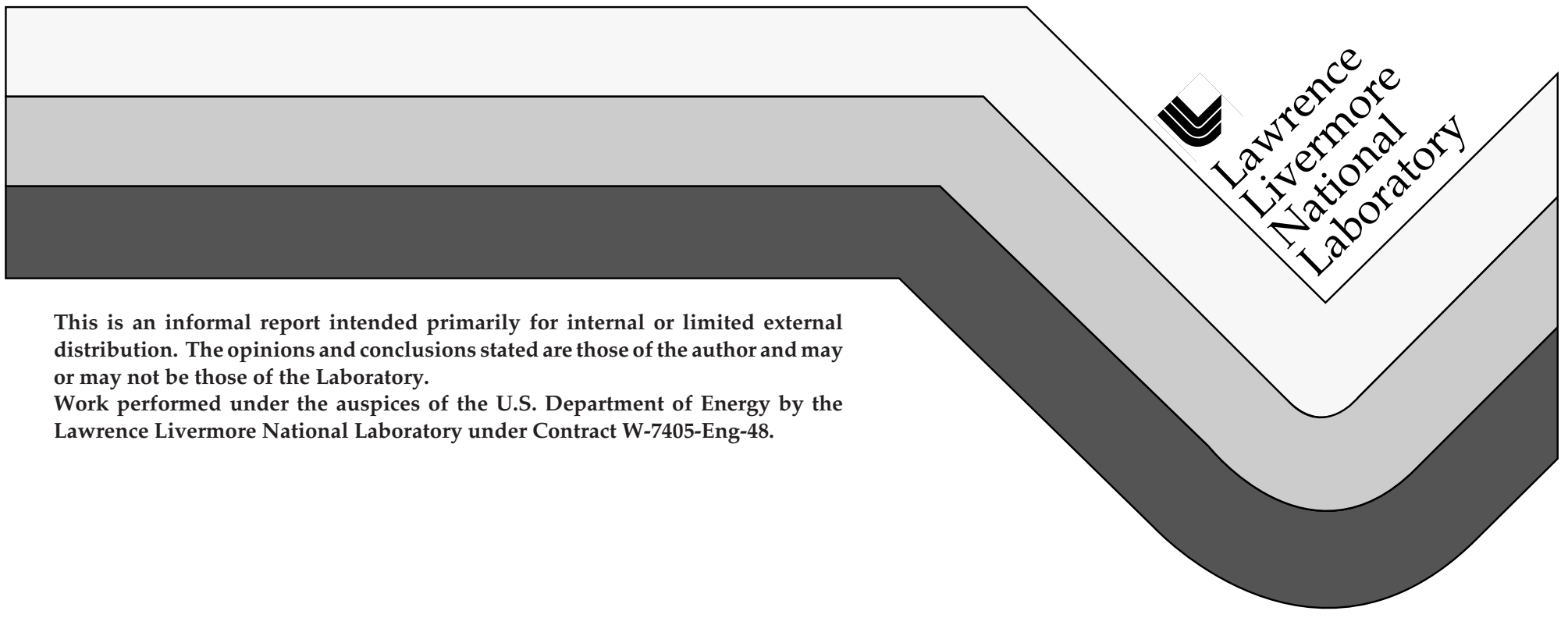




\section{DISCLAIMER}

This document was prepared as an account of work sponsored by an agency of the United States Government. Neither the United States Government nor the University of California nor any of their employees, makes any warranty, express or implied, or assumes any legal liability or responsibility for the accuracy, completeness, or usefulness of any information, apparatus, product, or process disclosed, or represents that its use would not infringe privately owned rights. Reference herein to any specific commercial product, process, or service by trade name, trademark, manufacturer, or otherwise, does not necessarily constitute or imply its endorsement, recommendation, or favoring by the United States Government or the University of California. The views and opinions of authors expressed herein do not necessarily state or reflect those of the United States Government or the University of California, and shall not be used for advertising or product endorsement purposes.

This report has been reproduced directly from the best available copy.

Available to DOE and DOE contractors from the Office of Scientific and Technical Information P.O. Box 62, Oak Ridge, TN 37831

Prices available from (423) 576-8401

Available to the public from the National Technical Information Service

U.S. Department of Commerce 5285 Port Royal Rd., Springfield, VA 22161 


\title{
ACtive Source ReQuirements for Assay of SLUdGe Drums ON THE BIR WIT SYSTEM
}

\author{
G. Patrick Roberson and David C. Camp
}

\section{INTRODUCTION:}

The design of the active source for active and passive computed tomography (A\&PCT) is critical with respect to accuracy and throughput. The A\&PCT active source requirements are highly dependent upon the attenuation properties of the waste matrix within the drum. One of the most highly attenuating waste matrices is sludge. This waste stream will consist of solidified aqueous waste consisting of IDC 001 first stage sludge and IDC 007 wet sludge. Also, the stream consists of solidified organic waste known as code IDC 003 organic setups. We have evaluated the sludge drum data that was previously acquired on the WIT system and have determined that the active source activity must be increased to provide reasonable throughput. The sludge drum that is evaluated here is drum CEPRF11. CEPRF11 is a test drum that was part of the Nondestructive Assay System Capability Evaluation Project (CEP) and contained an actual Rocky Flats waste that is categorized as code 003 solidified organic waste. The full drum was evaluated and found to be somewhat homogeneous; therefore, a single slice is arbitrarily chosen to represent the entire drum. Slice number 8 is used and is located approximately at the center of the drum. Figure 1 shows the averaged projections for different energies derived from the active sinogram of slice number 8 from the CEPRF11 drum. This is the average of all the projections of slice 8 taken over 180 degrees with an active integration time of 6 seconds. Figure 2 is also a graph showing the average of all the projections for slice 8 ; however, the active integration time is 30 seconds.

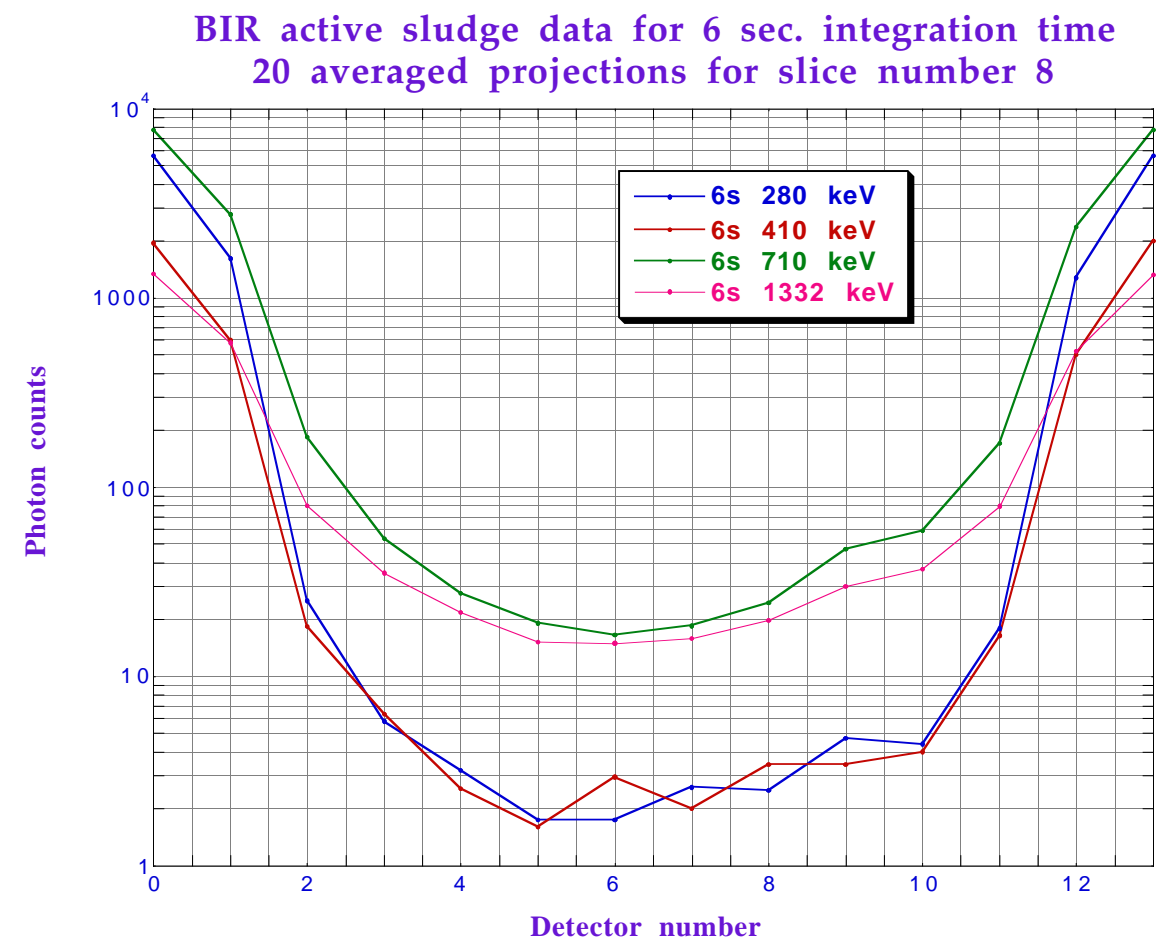

Figure 1: Averaged projections for slice 8 of drum CEPRF11 with 6 sec. active integration time. 
BIR active sludge data for 30 sec. integration time 20 averaged projections for slice number 8

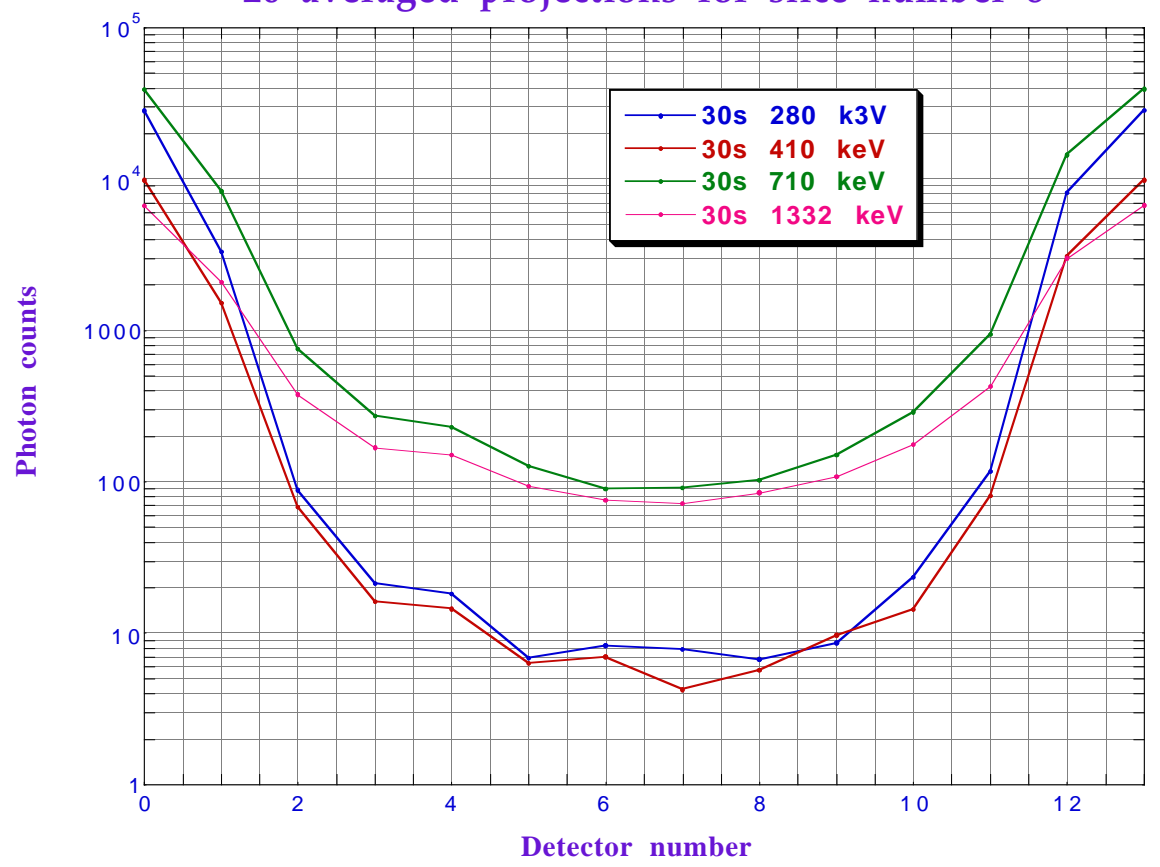

Figure 2: Averaged projections for slice 8 of drum CEPRF11 with 30 sec. active integration time.

From the graph shown in Figure 1 it is evident that the counting statistics of the detectors for cords located at the center of the drum are not sufficient for an accurate determination of the linear attenuation coefficient. With an integration time of 6 seconds, the center portion of the drum appears to be totally attenuated for energies at and below $410 \mathrm{keV}$. For energies above $710 \mathrm{keV}$ there appears to be penetration; however, the counting statistics are no better than $30 \%$. For an integration time of 30 seconds, as shown in Figure 2, there may be some penetration at and below $410 \mathrm{keV}$; however, the counting statistics are no better than $30 \%$. At $710 \mathrm{keV}$ and above the counting statistics are only $10 \%$.

Three conclusions can be made from the averaged projections of the CEPRF11 drum. First, a long integration time will be required for the active imaging of sludge drums if the active source activity remains the same. The integration time would need to be at least 30 seconds and most likely longer, which would yield unacceptable system throughput for sludge drums. Second, it would be an advantage to use the high energy peaks to extrapolate the linear attenuation coefficient at lower energies. Third, it would be an advantage to increase the active source activity, thereby increasing the active imaging throughput.

Figure 3 shows the active images for slice 8 of the CEPRF11 drum reconstructed from the 30 second data set. Notice that the two high energy reconstructions at $710 \mathrm{keV}$ and 1332 $\mathrm{keV}$ indicate that there may be two voids located in the bottom right of the drum. However, the two apparent voids are not as visible in the two lower energy reconstructions that are performed at $280 \mathrm{keV}$ and $410 \mathrm{keV}$. This may suggest that there is insufficient penetration at these energies for an accurate active image reconstruction. 


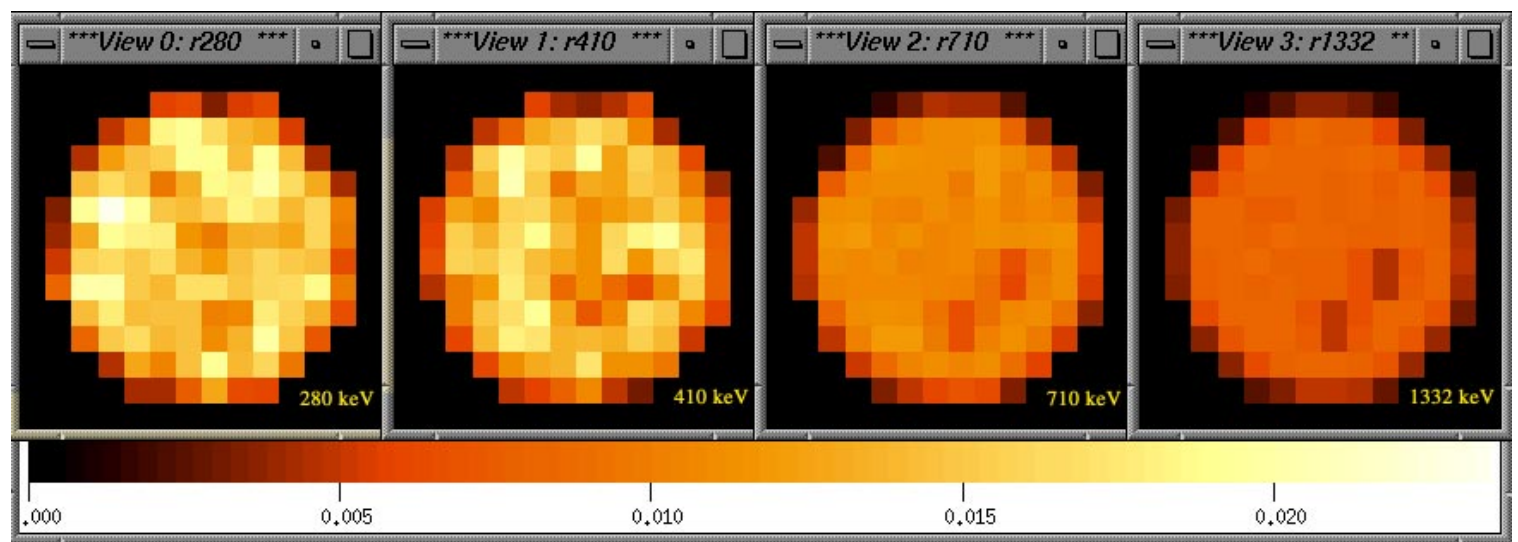

Figure 3: Active images at different energies from slice 8 of sludge drum CEPRF11 reconstructed from data with 30 second integration time.

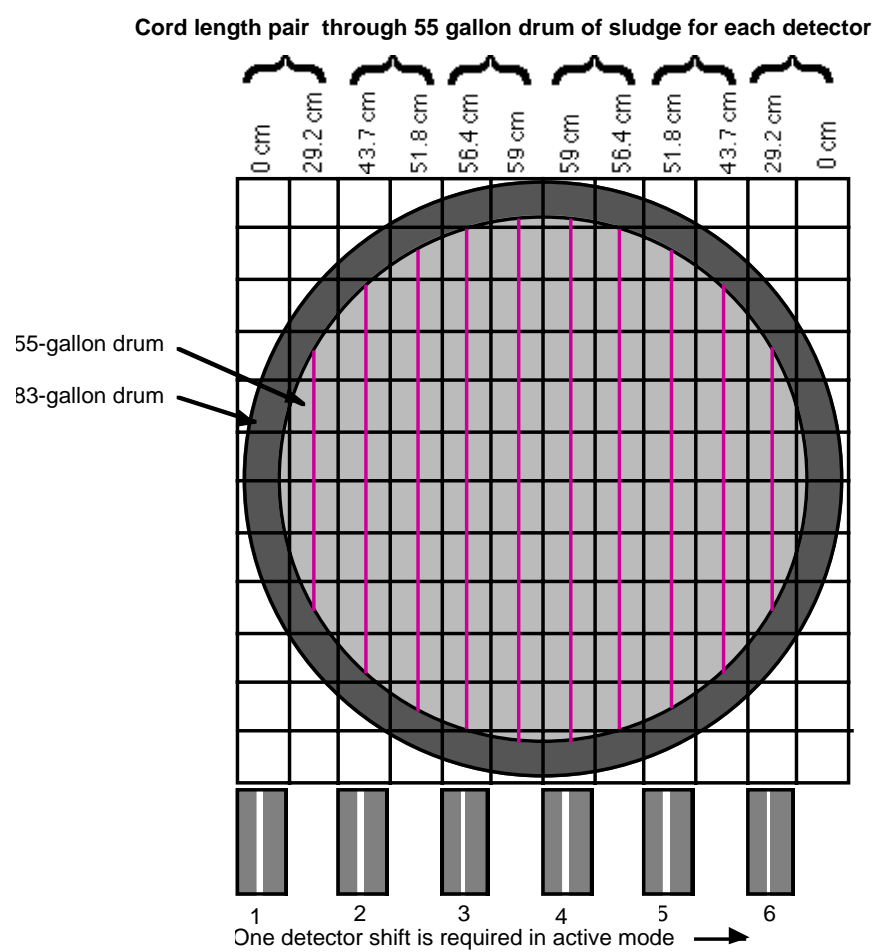

Figure 4: Active mode detector coverage of 55 and 83 gallon drums. In active mode the detectors are translated once for each projection acquired. The activemode cord length pair through a 55 gallon drum containing sludge is shown for each detector.

\section{SIMULATION:}

The active source activity required for assaying sludge drums on the WIT system can be better understood using simulation. The sludge drum can be modeled knowing the chemical makeup of the waste matrix material. The simulation was simplified by using only the dominant materials which make up approximately $90 \%$ of the sludge matrix. The chemical makeup of the sludge material is shown in Table 1. A bulk density of 1.1 is used for the sludge matrix simulation, which is derived from an average over several thousand actual 
drums at INEEL. This density value is somewhat less for code 003 sludge but should be accurate for codes 001, 002 and 007. Using this chemical makeup and the average bulk density, the linear attenuation is calculated at various energies from ${ }^{166 \mathrm{~m}} \mathrm{Ho},{ }^{60} \mathrm{Co}$, and ${ }^{152} \mathrm{Eu}$ active sources. Table 2 contains the linear attenuation coefficient for major peaks of the ${ }^{166 \mathrm{~m}} \mathrm{Ho},{ }^{60} \mathrm{Co}$, and ${ }^{152} \mathrm{Eu}$ sources. The linear attenuation coefficient is then used to determine the initial activity observed at the detector (Io) that is required to produce 100 counts per second (cps) after being absorbed by various cord lengths of sludge material. Figure 4 is a diagram of the proposed WIT multiple-detector system showing the location of detectors with respect to the expected active cord lengths for a 55 gallon drum containing sludge. The Io value is determined using the following formula:

$$
I o_{(100 c p s)}=\frac{I}{e^{-u \times l}},
$$

Where $I$ is the expected counts at the detector after attenuation of Io through a cord length $l$ of sludge material and the steel drum wall. $I o$ is calculated with a fixed $I$ of $100 \mathrm{cps}$. The cord length is variable from 0 to $60 \mathrm{~cm}$ depending on the location of the detector with respect to the drum. The linear attenuation coefficient, $\mu$, is dependent on energy and the value at each energy of interest is obtained using a LLNL simulation code called TPORT and recorded in Table 2 . Using the initial activity that is seen at the detector of the WIT system, the required activity of the active source can be determined using:

$$
\operatorname{Activity}_{(m C i)}=\frac{\left(I_{(100 c p s)}\right)}{d \Omega \times B r \times \varepsilon \times A r \times d p s_{(m C i)}},
$$

where $B r$ is the branching ratio of the energy peak of interest, $\varepsilon$ is the intrinsic peak efficiency of the detector, $A r$ is the correction factor used when the 5:1-aspect-ratio septa is inserted in the collimator aperture (the value is 0.8 for the current WIT configuration), and $d p s_{(m C i)}$ is $3.7 \times 10^{7}$ disintegrations per second required for one millicurie (mCi) unit of activity. The detector solid angle is denoted by $\Omega$ and is calculated using:

$$
d \Omega=\frac{A}{4 \times \pi \times d^{2}},
$$

where $A$ is the detector plane frontal area and $d$ is the detector to source distance. The detector frontal area of the single-detector WIT system is currently $5.398 \mathrm{~cm}^{2}$ and will be $5.715 \mathrm{~cm}^{2}$ after the multiple-detector upgrade. A detector to source distance of $118 \mathrm{~cm}$ is used in the solid angle calculation, which is the current single-detector geometry. However, the multiple-detector geometry is unknown at this time and the detector to source distance could differ slightly, but not substantially.

Table 1: Chemical recipe used to simulate a sludge drum

\begin{tabular}{|c|l|l|c|}
\hline Item & Constituent & Formula & $\begin{array}{l}\text { Amount } \\
(\% \text { weight })\end{array}$ \\
\hline 1 & Steel & $\mathrm{Fe}_{985} \mathrm{C}_{15}$ & 0.72 \\
\hline 2 & Sodium nitrate & $\mathrm{NaNO}_{3}$ & 34.6 \\
\hline 3 & Potassium nitrate & $\mathrm{KNO}_{3}$ & 12.8 \\
\hline 4 & Ferric sulfate & $\mathrm{Fe}_{2}\left(\mathrm{SO}_{4}\right)_{3} 9 \mathrm{H}_{2} \mathrm{O}$ & 7.9 \\
\hline 5 & Aluminum nitrate & $\mathrm{Al}\left(\mathrm{NO}_{3}\right)_{3} 9 \mathrm{H}_{2} \mathrm{O}$ & 19.5 \\
\hline 6 & Magnesium sulfate & $\mathrm{MgSO}_{4} 7 \mathrm{H}_{2} \mathrm{O}$ & 15.5 \\
\hline 7 & Calcium chloride & $\mathrm{CaCl}_{2}$ & 9 \\
\hline
\end{tabular}


Table 2: Energy-dependent information used to determine the active source activity required from ${ }^{166 m} \mathrm{Ho}$ and ${ }^{60} \mathrm{Co}$ sources.

\begin{tabular}{|l|l|c|c|}
\hline \multicolumn{4}{|c|}{ Energy-dependent information for the ${ }^{166 \mathrm{~m}} \mathrm{Ho} \&{ }^{60}$ Co sources } \\
\hline Energy $(\mathrm{keV})$ & $\begin{array}{c}\text { Attenuation } \\
\text { coefficient } \\
(\mu \text { in 1/cm })\end{array}$ & $\begin{array}{c}\text { Intrinsic peak } \\
\text { efficiency }(\varepsilon)\end{array}$ & $\begin{array}{c}\text { Branching ratio } \\
(\mathrm{Br})\end{array}$ \\
\hline $280\left({ }^{166 \mathrm{~m}} \mathrm{Ho}\right)$ & 0.1286 & 0.544 & 0.305 \\
\hline $410\left({ }^{166 \mathrm{~m}} \mathrm{Ho}\right)$ & 0.1103 & 0.435 & 0.119 \\
\hline $710\left({ }^{166 \mathrm{~m}} \mathrm{Ho}\right)$ & 0.0867 & 0.3 & 0.602 \\
\hline $1332\left({ }^{60} \mathrm{C} 0\right)$ & 0.0637 & 0.2 & 1.0 \\
\hline
\end{tabular}

Table 3: Energy-dependent information used to determine the active source activity required from $a^{152}$ Eu source.

\begin{tabular}{|c|c|c|c|}
\hline \multicolumn{4}{|c|}{ Energy-dependent information for the ${ }^{152}$ Eu source } \\
\hline Energy $(\mathrm{keV})$ & $\begin{array}{c}\text { Attenuation } \\
\text { coefficient } \\
(\mu \text { in } 1 / \mathrm{cm})\end{array}$ & $\begin{array}{c}\text { Intrinsic peak } \\
\text { efficiency }(\varepsilon)\end{array}$ & $\begin{array}{c}\text { Branching ratio } \\
(\mathrm{Br})\end{array}$ \\
\hline 121 & 0.185 & 0.65 & 0.282 \\
\hline 344 & 0.1184 & 0.484 & 0.263 \\
\hline 778 & 0.0832 & 0.28 & 0.128 \\
\hline 964 & 0.0751 & 0.24 & 0.144 \\
\hline 1402 & 0.0621 & 0.19 & 0.206 \\
\hline
\end{tabular}

Table 4: Energy-dependent information used to determine the active source activity required from $a^{133} \mathrm{Ba}$ source.

\begin{tabular}{|c|c|c|c|}
\hline \multicolumn{4}{|c|}{ Energy-dependent information for the ${ }^{133}$ Ba source } \\
\hline Energy $(\mathrm{keV})$ & $\begin{array}{l}\text { Attenuation } \\
\text { coefficient } \\
(\mu \text { in } 1 / \mathrm{cm})\end{array}$ & $\begin{array}{c}\text { Intrinsic peak } \\
\text { efficiency }(\varepsilon)\end{array}$ & $\begin{array}{c}\text { Branching ratio } \\
(\mathrm{Br})\end{array}$ \\
\hline 356 & 0.1168 & 0.48 & 0.62 \\
\hline
\end{tabular}

Figure 5-7 are graphs that show the required activity to achieve 100 counts per second at the detector after being attenuated by various cord lengths of sludge material within a 55 gallon steel drum. Each of the graphs have gray shaded areas that represent the cord-length coverage for each detector depending on its position with respect to the sludge drum. Figure 5 shows the required activity for four different energies from the current singledetector configuration consisting of ${ }^{166 \mathrm{~m}} \mathrm{Ho}$ and ${ }^{60} \mathrm{Co}$ sources. Figure 6 shows the activity required for five different energies of an ${ }^{152} \mathrm{Eu}$ source. This activity is determined for the new multiple-detector configuration that will have a slightly larger collimator aperture than the current single-detector configuration. Figure 7 shows the activity that would be required form the $356 \mathrm{keV}$ peak of a ${ }^{133} \mathrm{Ba}$ source and compares the activity to that required by the $344 \mathrm{keV}$ peak of an ${ }^{152} \mathrm{Eu}$ source. Both calculations are made for the multiple-detector configuration. 
Rearranging Equation 2 and solving for the unattenuated counts expected at the detector (Io) yields:

$$
I o=\text { Activity }_{(m C i)} \times d \Omega \times B r_{(\Sigma)} \times \mathcal{E} \times A r \times d p s_{(m C i)},
$$

where the branching ratios are summed for all the source peaks and the intrinsic peak efficiency of the detector is fixed at 0.58 , which will provide the greatest Io counts at the detector (worst case scenario) for the current detector configuration in the WIT system. Expected unattenuated counts verses active source activity are plotted in Figure 8.

Ho166 active source activity required for $100 \mathrm{cps}$ at the detector for a 55 gallon drum with $1.1 \mathrm{~g} / \mathrm{cc}$ bulk density sludge.

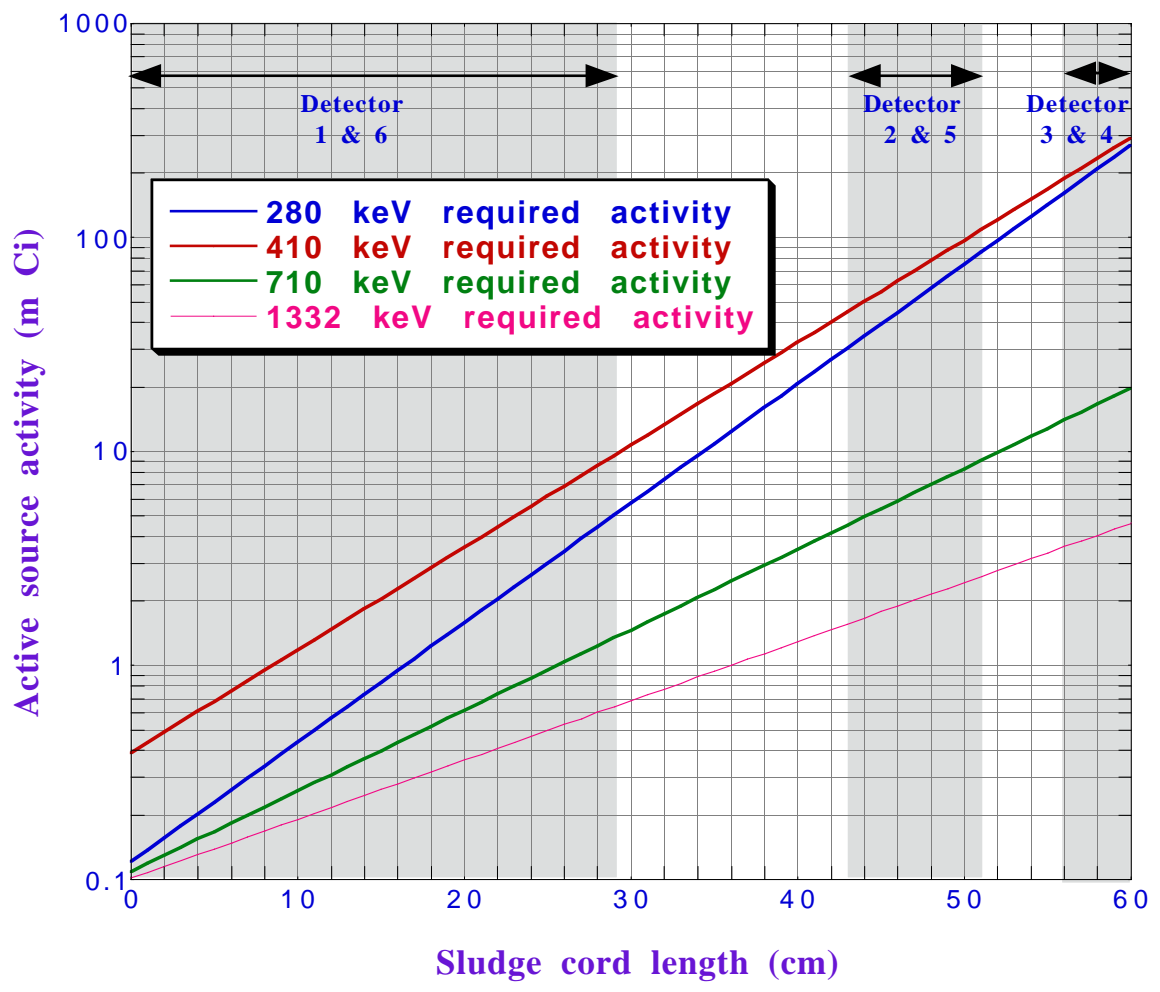

Figure 5: Activity of ${ }^{166 m} \mathrm{Ho}$ and ${ }^{60} \mathrm{Co}$ required at four different energies to produce 100 counts per second at the detector after being attenuated by various cord lengths of sludge material. The gray shaded area shows the cord length coverage for each detector of the new multiple-detector design. 
Eu152 active source activity required for $100 \mathrm{cps}$ at the detector for a 55 gallon drum with $1.1 \mathrm{~g} / \mathrm{cc}$ bulk density sludge.

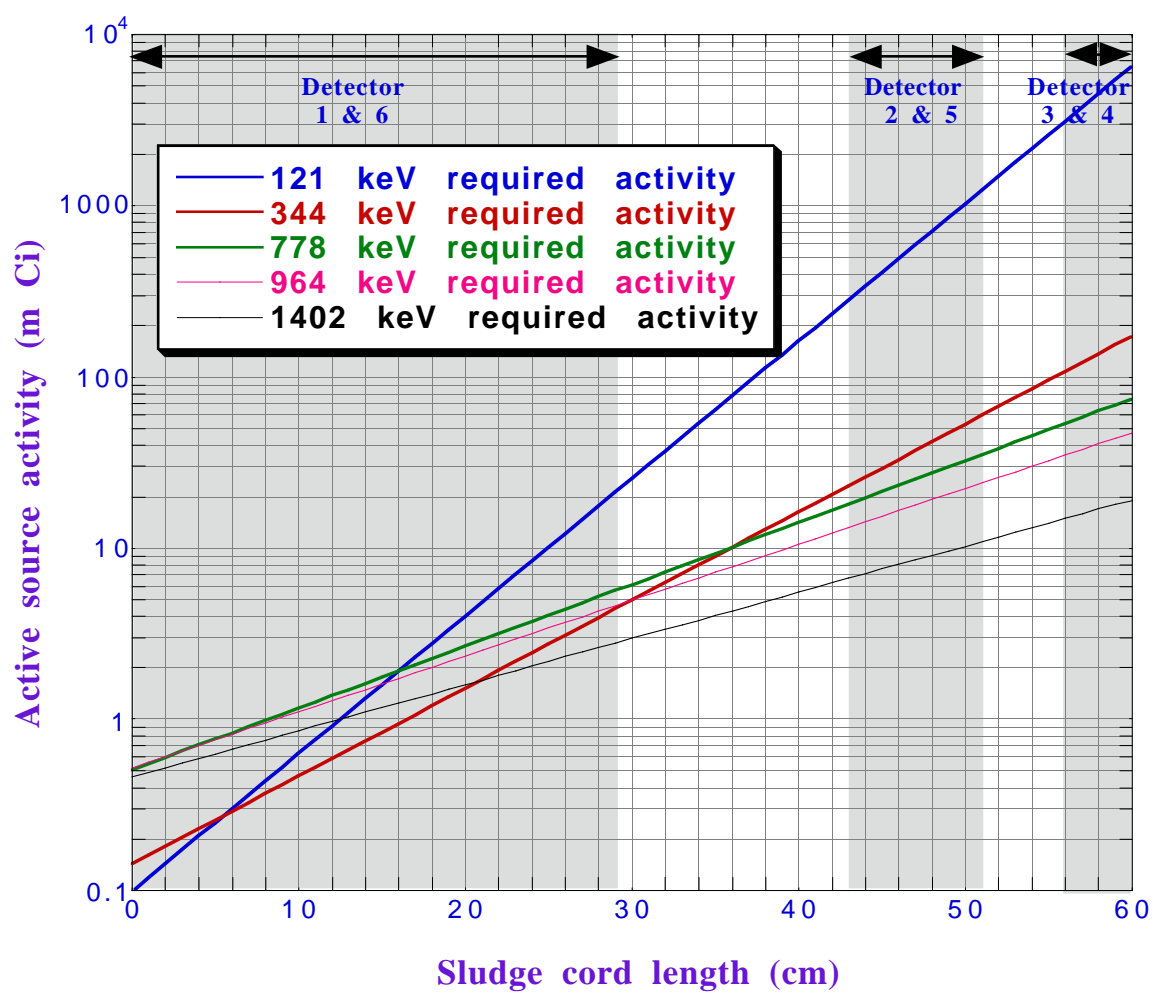

Figure 6: Activity of ${ }^{152}$ Eu required at five different energies to produce 100 counts per second at the detector after being attenuated by various cord lengths of sludge material.

\section{CONCLUSION:}

Reasonable system throughput for assaying sludge drums will require greater active source strength than what is currently used on the WIT A\&PCT scanner. Unfortunately, increasing the source activity too much will swamp the detector system when measuring the initial beam (Io) or when any cord is measured that has little attenuation. However, for sludge drums with uniform attenuation properties, it might be an advantage to have an active source with variable activity. The active source might have two activities. This could be accomplished by automatically positioning the source so that either a standard strength source or a source with increased activity is positioned in front of the source collimator aperture. It is possible that the initial (unattenuated) beam of the stronger sources cannot be measured. If this is the case, the Io determination can be calculated instead of measured.

The digital gamma-ray spectrometer (DSPec) is capable of count rates of 140,000 counts per second. If the unattenuated count rate was limited to 100,000 counts per second, the active source activity could be approximately $10 \mathrm{mCi}$ of ${ }^{166 \mathrm{~m}} \mathrm{Ho}, 20 \mathrm{mCi}$ of ${ }^{152} \mathrm{Eu}$ or $30 \mathrm{mCi}$ of ${ }^{133} \mathrm{Ba}$. However, the amount of dead time generated by any of these active source activities is unknown and should be evaluated.

There is a choice that must be made with respect to the method of determining the linear attenuation coefficient . First, it could be determined, as it is currently, by using a direct measurement of attenuation at the energy of interest or by interpolating between two different energy peaks. Second, $\mu$ could be determined by extrapolating from the higher 
energy peaks only. The extrapolation method would not be as accurate as making direct measurements or interpolating; however, less activity would be required if only high energy peaks were used.

Another choice must be made with respect to the type of source or sources to use. A comparison of the ${ }^{133} \mathrm{Ba}$ and ${ }^{152} \mathrm{Eu}$ activity required to generate $100 \mathrm{cps}$ at approximately $350 \mathrm{keV}$ through various sludge cords is shown in Figure 6. This graph illustrates that ${ }^{133} \mathrm{Ba}$ at $356 \mathrm{keV}$ will provide the necessary counts with less activity than ${ }^{152} \mathrm{Eu}$ at $344 \mathrm{keV}$ because ${ }^{133} \mathrm{Ba}$ has a higher branching ratio. The tradeoff is that ${ }^{133} \mathrm{Ba}$ will require another source mixed with it to get the necessary high energy peaks and will cost more than the ${ }^{152} \mathrm{Eu}$ source which can be used by itself.

From graphs shown in Figures 5-7 it appears that a standard ${ }^{152}$ Eu source activity of approximately $4 \mathrm{mCi}$ would provide sufficient strength at $344 \mathrm{keV}$ and there would be no need to increase the source strength for detector 1 and 6 . The required additional source strength for detectors 2 and 5 would be approximately $50 \mathrm{mCi}$ and for detectors 3 and 4 the requirement is $170 \mathrm{mCi}$ to generate $100 \mathrm{cps}$ at the detector. This scenario may be the ideal situation; however, it may not be possible to get source strengths of this magnitude due to a restriction of the physical size of the source container. Additionally, sources with activities greater than $10 \mathrm{mCi}$ exceed the current allowable threshold at BIR; therefore, there is a limit of $10 \mathrm{mCi}$ for the active source activity.

Ba133 \& Eu152 active source activities required for 100 cps at the detector for a 55 gallon drum with $1.1 \mathrm{~g} / \mathrm{cc}$ bulk density sludge.

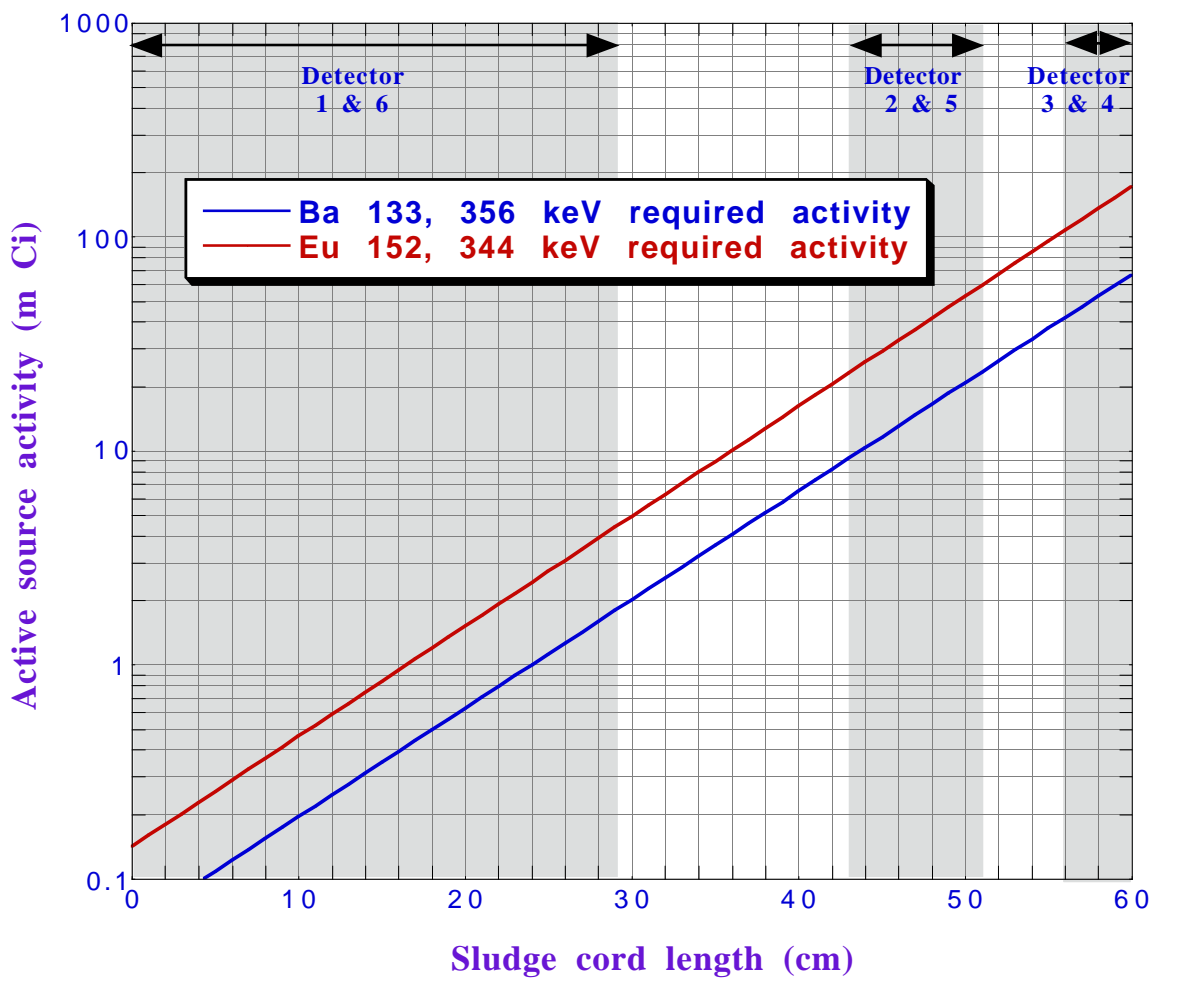

Figure 7: Activity of ${ }^{152} \mathrm{Eu} 344 \mathrm{keV}$ peak and ${ }^{133} \mathrm{Ba} 356 \mathrm{keV}$ peak required to produce 100 counts per second at the detector after being attenuated by various cord lengths of sludge material. 
Unattenuated counts expected at the detector as a function of source activity.

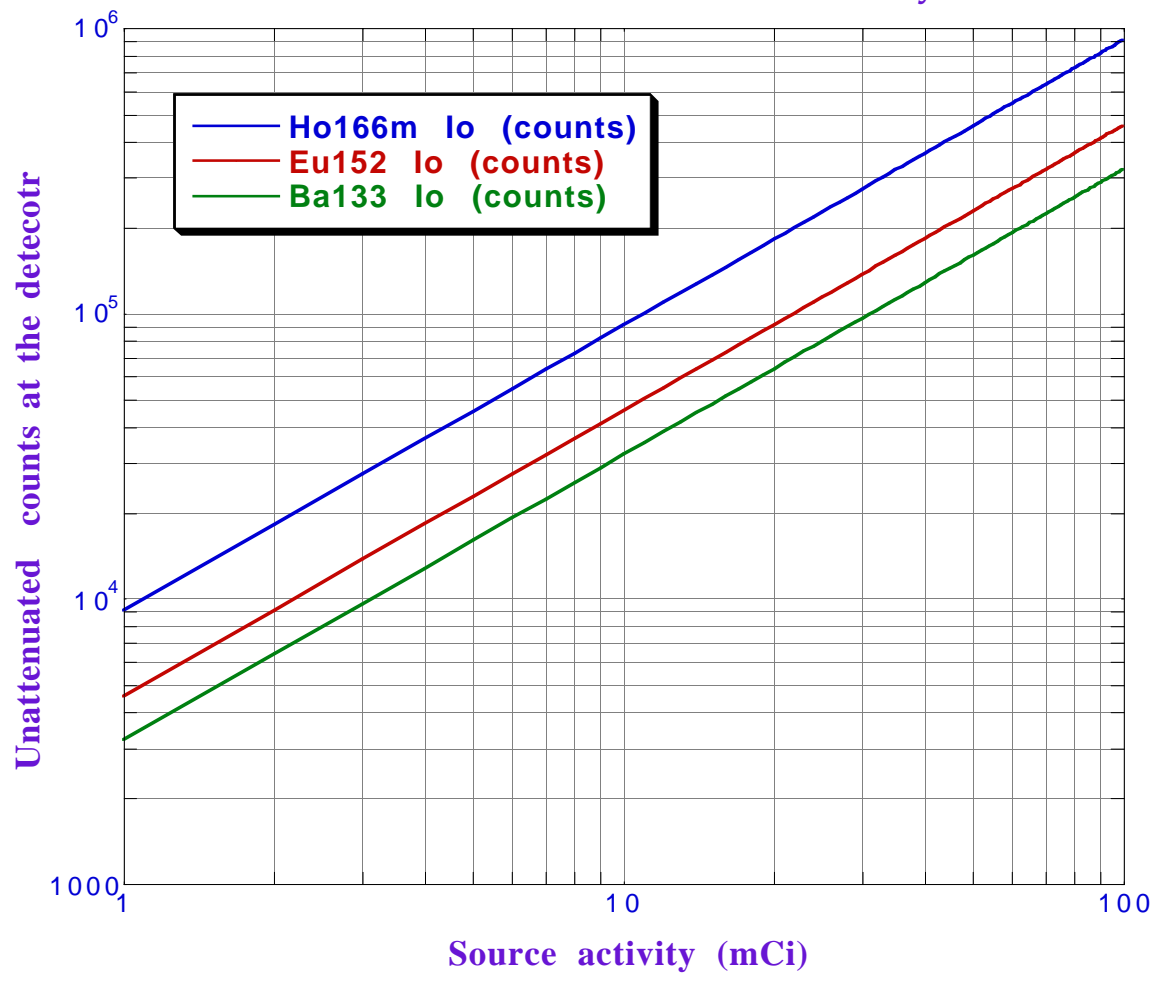

Figure 8: Initial counts expected at each of the multiple detectors for a given active source activity. The intrinsic peak efficiency of the new detectors is unknown, however, for this calculation it is fixed at 0.58 which represents the worst case scenario of the current detector used in the WIT A\&PCT system.

If the active source is limited to $10 \mathrm{mCi}$, it will take approximately 17 seconds to get 100 counts at the center detectors when assaying an average sludge drum. This would reduce the throughput significantly. However, there is another possible solution. A drum that is truly homogeneous will have active projections that are identical over all angles. The homogeneity of a sludge drum can be evaluated by transmission tomography (TCT) or digital radiography (DR) using the linear accelerator and linear detector system within the WIT trailer. If a drum is found to be homogeneous, a single measured projection could be simply duplicated 18 times to produce the required sinogram for active reconstruction. If the drum is homogeneous over all slices, a single projection could be used to reconstruct the entire 3D active image. This is a form of limited angle tomography and should be valid for drums that are truly homogeneous. A single projection of a sludge drum could be acquired in 100s of seconds providing much better counting statistics and yet increase throughput significantly. 



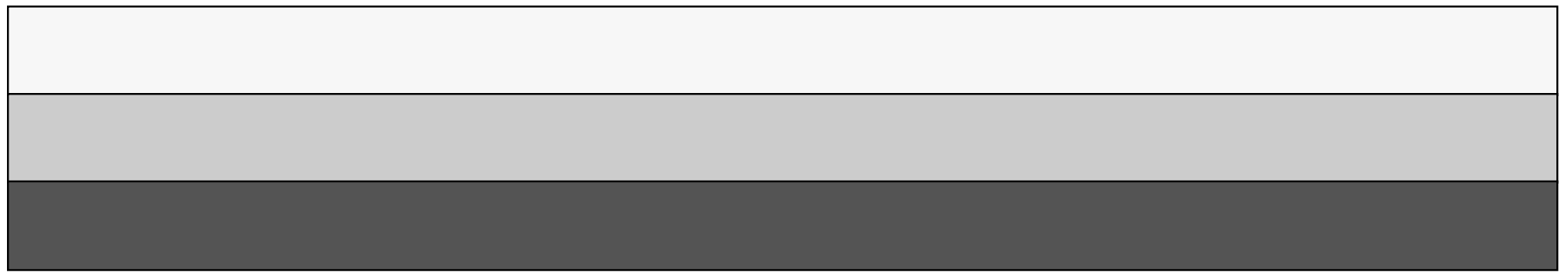

